\title{
EFFECT OF 20-METHYLCHOLANTHRENE ON MOUSE EMBRYOS. II. STRAIN C3H (JAX)
}

\author{
LALITA D. SAVKUR, B. K. BATRA AND B. N. SRIDHARAN \\ India Cancer Research Centre, Parel, Bombay-12, India
}

(Received 14th February 1961)

\begin{abstract}
Summary. Injection of a microquantity of 20-methylcholanthrene has been made into the fluids of 10-day-old embryos of mice of the $\mathrm{C} 3 \mathrm{H}$ (Jax) strain. The treatment resulted in increased prenatal mortality of the embryos and many of the surviving young also showed morphological abnormalities. Examination of the young at weaning age revealed certain deformities and pathological conditions. The relation of some of the abnormalities to naturally occurring mutations is significant. An additional observation was the occurrence of similar abnormalities in the litters born after the treated litter.

Since the abnormalities in the present study resemble the ones observed in a similar investigation conducted earlier, as well as the ones caused by irradiation and other teratogenic agents, it is proposed that the mode of action of the carcinogen might also be the same.
\end{abstract}

\section{INTRODUCTION}

Several extrinsic agents have been known to cause maldevelopment in the mammalian embryo. The teratogenic effects of Roentgen rays and chemicals have been unequivocally illustrated (Hicks, 1953; Lee, Wiseman, Kaplan \& Warkany, 1955; Fraser, Kalter, Walker \& Fainstat, 1954). Interesting findings have also been reported following treatment with certain carcinogens. Smith \& Rous (1948) injected Urethane intraperitoneally in advanced pregnant mice of C strain and observed lung tumours in the young as early as 3 days post partum. Furthermore, Law (1940) injected 1:2:5:6-dibenzanthracene directly into the amniotic fluids of 14-day-old mouse embryos. He reported an increase in the percentage of lung tumours in the young, without any reference to congenital malformations. Jackson \& Robson (1958) injected methylcholanthrene in rabbit embryos by intra-amniotic and intra-placental injections and observed interruption of pregnancy. In our laboratory, methylcholanthrene was injected in the amniotic fluid of mouse embryos of the strain Swiss Albino and certain striking abnormalities were noticed in the young born, as well as in the subsequent litters born to the mother (Savkur, Batra \& Sridharan, 1960).

It was in the light of the above work that it was considered worthwhile to evaluate the effect of a single small dose of a carcinogen, 20-methylocholanthrene, on mouse embryos of a highly susceptible cancer strain, namely $\mathrm{C} 3 \mathrm{H}$ (Jax), at a very sensitive stage of their prenatal development, i.e. 10th day. 


\section{MATERIAL AND METHODS}

Pregnant females at the 10th day of gestation were anaesthetized with ether and the hair on the abdomen was clipped. By means of midventral incisions, the abdomen was opened and the uterine horns exposed. With a Tuberculin syringe fitted with a No. 26 needle, $0.01 \mathrm{cc}$ of the test solution was injected directly into the embryonic fluid of each embryo. The incisions in the abdominal walls were sutured and the operated females were checked daily thereafter.

The litters born were checked at birth for morphological appearance and were maintained till weaning age at which time they were autopsied. The operated mothers were then put back for mating without any further treatment and the data on subsequent litters were collected. This breeding was conducted to see particularly whether the carcinogen treatment during one of the pregnancies would have any effects on the litters born subsequently to the animal, because that would imply changes in the system during the treatment which continues even later in the animal's life.

The following groups were maintained:

1. Primiparous females treated with (a) $0.025 \%$ methylcholanthrene, $(b)$ Tyrode's solution (control).

2. Multiparous females treated with $(a) 0.025 \%$ methylcholanthrene, $(b)$ $0.25 \%$ methylcholanthrene.

3. Untreated control breeders.

\section{OBSERVATIONS}

OBSERVATIONS ON TREATED LITTERS

In order to evaluate the mortality factor involved following the treatment, the number of embryos in each uterine horn was recorded. At full-term, it was observed that many of the carcinogen-treated females had total resorption; even among those that delivered, the total number of foetuses recovered was considerably less than the number treated. The prenatal mortality was calculated as the total number of young developing to term as against the number of embryos treated.

Many of the young that survived till term showed a variety of abnormalities. These were chiefly seen in the litters born after carcinogen treatment. The abnormalities were subcutaneous haemorrhages (Pl. 1, Figs. 1, 2 and 3), tail variations (Pl. 1, Fig. 4) and monstrosities (Pl. 2, Fig. 5). When these young were autopsied on the 21st day, a few conditions including cystic kidney and cystic uteri were seen.

Prenatal mortality. As seen from Table 1, the foetuses in the $0.025 \%$ primiparous group show considerable embryonic resorption $(72.1 \%)$, and this mortality is significantly higher than that of the $0.025 \%$ multiparous group (Table 2). The stronger dose, i.e. $0.25 \%$ methylcholanthrene, was toxic and caused the death of most of the embryos $(85.1 \%)$. In the control Tyrode group, a minimum number of embryos was resorbed. The prenatal mortality in all the three carcinogen-treated groups was significantly higher than that of the Tyrode group (Table 2). 
Lalita D. Savkur et al.

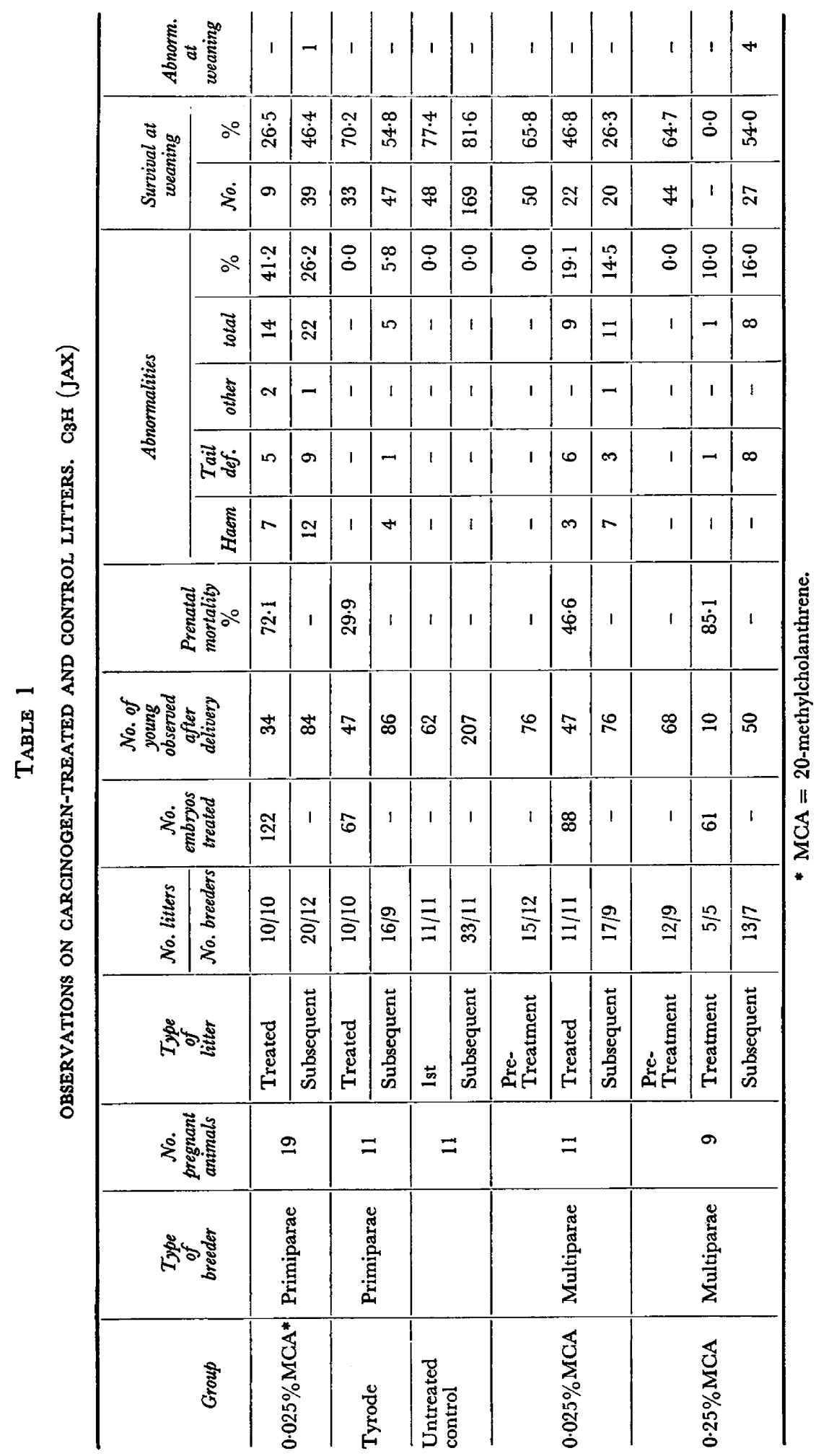


Abnormalities. Among the groups, the largest number of abnormalities was observed in the $0.025 \%$ primiparous group $(41.2 \%)$ and this was significantly higher than that of the $0.025 \%$ multiparous group (Table 2). It is surprising and significant to observe that in the $0.25 \%$ multiparous group, where the dose was ten times stronger, the abnormalities did not increase proportionately. Only ten young were born and among them only one case of tail deformity was noticed. In the Tyrode-treated litters, there was not a single abnormality of any kind, as a striking contrast to the different abnormalities noticed in the other three groups.

TABLE 2

CHI-SQUARE VALUES

\begin{tabular}{|c|c|c|c|}
\hline Groups compared & $\begin{array}{l}\text { Prenatal } \\
\text { mortality }\end{array}$ & $\begin{array}{c}\text { Abnormali- } \\
\text { ties }\end{array}$ & $\begin{array}{c}\text { Survival } \\
\text { till weaning }\end{array}$ \\
\hline $\begin{array}{l}0.025 \% \text { primiparae } \\
0.025 \% \text { multiparae }\end{array}$ & $14 \cdot 07 \dagger$ & $4 \cdot 71^{*}$ & $3 \cdot 45$ \\
\hline $\begin{array}{l}0.025 \% \text { primiparae } \\
\times \\
\text { Tyrode primiparae }\end{array}$ & $31.57 \dagger$ & \pm 5 & $15 \cdot 12 \dagger$ \\
\hline $\begin{array}{l}0.025 \% \underset{\times}{\text { multiparae }} \\
\text { Tyrode primiparae }\end{array}$ & $4 \cdot 46^{*}$ & $\$ \S$ & 0.53 \\
\hline $\begin{array}{l}0.25 \% \text { multiparae } \\
\times \\
\text { Tyrode primiparae }\end{array}$ & $37.35 \dagger$ & $4 \cdot 78^{*}$ & $13.91 \dagger$ \\
\hline
\end{tabular}

$I \S$ Apparently very highly significant; values not calculated.

Survival till weaning. Considering the survival rates among the four groups, the litters of $0.25 \%$ multiparae seem to have been greatly affected, for none of the ten born survived till the 21 st day. The survival rate is also quite low in the litters of $0.025 \%$ primiparae $(26.5 \%)$. As a contrast, the Tyrode-treated litters have a survival rate of $70.2 \%$, which is significantly higher than those of the two carcinogen-treated groups mentioned above (Table 2).

Abnormalities observed at weaning. All the young were killed at weaning age and their viscera carefully examined. In all the four groups, no abnormality was discernible.

\section{OBSERVATIONS ON SUBSEQUENT LITTERS}

The subsequent litters in the present study include the litters born to the operated animals after the weaning of the treated litters. Only the litters obtained until a certain period are reported (Table 1). From the results, it is noted that the various abnormalities observed in the treated litters were seen to persist in the subsequent litters of the different groups. The haemorrhages were 
found to be more common than the tail deformities. Among the other abnormalities observed at birth, one was a monster in the $0.025 \%$ primiparous group and a case of dwarfism was noticed in the $0.025 \%$ multiparous group, where a female was extremely small when compared to its litter-mates (Pl. 2, Fig. 6). Of the young autopsied at weaning age, in the $0.025 \%$ primiparous group one male had a cystic kidney (Pl. 2, Fig. 7). In the $0.25 \%$ multiparous group, of the twenty-seven young autopsied, one female was a dwarf (Pl. 2, Fig. 8). In two females, stimulated uterine horns filled with fluid were observed (Pl. 2, Fig. 9). Histological study suggested hypersecretion of oestrogen at an age as early as 21 days. The multiparous breeders were allowed to have one or two litters before they were taken for treatment, so that the pretreatment litters could be compared with the litters born after the treatment. The young born in the pretreatment litters did not have any abnormality.

\section{DISGUSSION}

The importance of the genetic constitution with particular reference to neoplastic tendencies has been amply demonstrated in cancer research for many years. Its role in the response to carcinogenic substances has also been emphasized. However, it is not clear whether embryonic tissue with its peculiar characteristics responds in the same manner as differentiated adult tissue does, and the present experiment is therefore an extension of work on embryonic tissue involving the highly susceptible $\mathrm{C} 3 \mathrm{H}(\mathrm{Jax})$ strain of mouse. Although the emphasis of the present experiment is on embryonic tissue reactions, it might be mentioned that the treated adults did not have a significantly earlier appearance of tumours following the introduction of the carcinogen into the body of the animal. A later paper is to deal in detail with this aspect of the problem.

The most significant response of the embryos following treatment in utero on the 10th day of gestation is the rather high percentage of abnormalities as compared to the Tyrode-treated controls and untreated controls. The two major abnormalities observed were haematomas and tail deformities. Job, Leibold \& Fitzmaurice (1935) and Russell (1950) have shown that the 10th day of gestation is indeed a sensitive stage in the development of embryos. Gluecksohn-Schoenheimer (1945) has also shown that during prenatal life specific loci are affected in certain known mutants such as the Sd mutant. In these, it has been observed that haematomas appear in the tail during the period of tail development which results in abnormal tails at birth. Waddington \& Carter (1952) and Hamburgh (1954), in experiments with trypan blue on embryos, also noticed a similar relationship between processes of development during prenatal life and expression at birth. It is therefore possible that the tail deformities observed may have been associated with haematomas during the critical period of tail development of the embryos (Gluecksohn-Schoenheimer, 1945).

As regards the formation of the haematomas seen in the young, adequate investigations have not been carried out, and therefore the role played by the carcinogen in their appearance is not known. However, the same observations have been recorded by Bagg \& Little (1924) and Russell (1950) in their work 
on the effect of radiation on embryos. The histology of the haemorrhagic areas show only that there has been a leakage of blood from the capillaries into the subcutis. It might be mentioned here that Bagg (1922) presents similar data on his work with mice embryos.

The occurrence of monsters is one of the drastic effects seen in the carcinogentreated young. Such effects are also seen following radiation treatment, and this appears also to be a lethal effect.

As seen from the histogram (Text-fig. 1), the correlation of prenatal mortality and total abnormalities is graphic. When a very strong dose of the carcinogen is administered to the embryos, mortality is highest with a naturally low incidence of abnormalities. Also to be taken into consideration is the number of animals in which total or partial resorption has taken place following the treatment. Grüneberg (1952) and Gluecksohn-Waelsch (1954) have both stated the direct effect of major abnormalities on mortality, and according to them young with major abnormalities seldom survive. As regards survival till weaning, it is

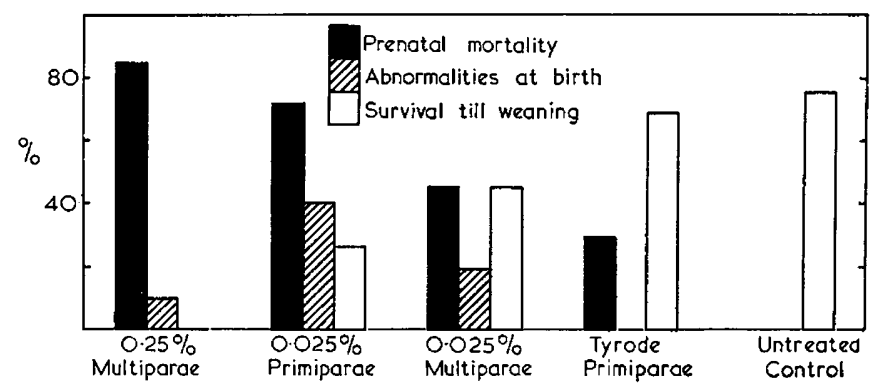

TeXT-FIG. 1. Relation between prenatal mortality, abnormalities at birth and survival till weaning in treated litters and their controls.

inversely proportional to the mortality before parturition. Lengerova (1958) in studying the effects of intra-uterine irradiation of rats in relation to the developmental stage at the time of exposure, found that for both prenatal and postnatal mortality the 9th day is the most sensitive. She adds that prenatal and postnatal mortality cannot be regarded as two fundamentally different phenomena. However, it is quite possible that the increased mortality between birth and weaning could have been at least in part attributable to the small number of young per litter being suckled by the treated females. On considering the three factors in the groups when divided into primiparae and multiparae, certain interesting observations can be seen as shown by the histogram. However, what role the carcinogen has had in this is certainly obscure.

A curious finding was the occurrence of abnormalities in the litters born subsequent to the treated litter. This is slightly puzzling because the possibility of a microquantity of the substance - injected, moreover, directly into the embryonic fluids - having effect after a considerable lapse of time is very remote. Whether the carcinogen is retained in the uterus or the effect of the carcinogen persists, has not been possible to discern in the present experiment. Further extensive investigations are therefore needed. 


\section{REFERENCES}

BAGG, H. J. (1922) Disturbances in mammalian development produced by radium emanation. Amer. $\mathcal{F}$. Anat. 30, 133.

BaGG, H. J. \& Little, G. C. (1924) Hereditary structural defects in the descendants of mice exposed to roentgen ray irradiation. Amer. F. Anat. 33, 119.

Fraser, F. G., Kalter, H., Walker, B. E. \& Fainstat, T. D. (1954) Experimental production of cleft palate with cortisone and other hormones. F. cell. comp. Physiol. 43, 237.

Gluecksohn-Schoenheimer, S. (1945) The embryonic development of mutants of the Sd-strain in mice. Genetics, 30, 29.

Gluecksohn-Waelsch, S. (1954) Some genetic aspects of development. Cold Spr. Harb. Symp. quant. Biol. 19, 41.

Grüneberg, H. (1952) The genetics of the mouse. Martinus Nijhott, The Hague.

Hamburgh, M. (1954) Embryology of trypan blue induced abnormalities in mice. Anat. Rec. 119, 409.

Hrcks, S. (1953) Developmental malformations produced by radiation. A time-table of their development. Amer. F. Roentgen. 69, 272.

Jackson, J. \& Robson, J. M. (1958) The effect of methylcholanthrene on growth and pregnancy. Brit. 7. exp. Path. 39, 133.

Job, T. T., Leibold, G. J. \& Fitzmaurice, H. A. (1935) Biological effects of roentgen rays. The determination of critical period in mammalian development with X-rays. Amer. F. Anat. 56, 97.

LAw, L. W. (1940) The production of tumours by injection of a carcinogen into the amniotic fluid of mice. Science, $91,96$.

Lee, C. M., Wiseman, J. T., Kaplan, S. A. \& Warkany, J. (1955) Effect of ethionine injections on pregnant rats and their offspring. Arch. Path. (Lab. Med.) 59, 232.

LENGEROVA, A. (1958) Lethal effects of intrauterine irradiation of rats in relationship with the developmental stage at the time of exposure. Excerpta med. Cancer, 6, 1197.

Russelr, L. B. (1958) X-ray induced developmental abnormalities in the mouse and their use in the analysis of embryological patterns. I. External and gross visceral changes. F. exp. Zool. 114, 545.

Savkur, Lalita D., Batra, B. K. \& Sridharan, B. N. (1960) The effect of 20-methylcholanthrene on mouse embryos. (In press.)

SмIтн, W. E. \& Rous, P. (1948) The neoplastic potentialities of mouse embryo tissues. IV. Lung adenomas in baby mice as a result of pre-natal exposure to urethane. 7. exp. Med. 88, 529.

Waddington, C. H. \& CARTER, T. C. (1952) Malformations in mouse embryos induced by trypan blue. Nature, Lond. 169, 27.

\section{EXPLANATION OF PLATES}

\section{PLATE 1}

Fig. 1. A newborn mouse showing a blood clot in the middle of the tail.

FIG. 2. A young mouse with haemorrhage on snout and right hind leg.

Fig. 3. Young mouse showing extensive haemorrhage on the head (right), along with its normal litter-mate (left).

FIG. 4. Young mouse with a 'curly' tail.

\section{PLATE 2}

Fig. 5. Monster with extensive haemorrhage on the head and rear portion of the body. The young mouse on the right is normal.

Frg. 6. A dwarf with its normal litter-mate on the left.

Fig. 7. A 21-day-old mouse with a cystic kidney.

Frg. 8. A 21-day-old dwarf with its normal litter-mate on the left.

FIG. 9. Cystic uterus observed at weaning age. 


\section{PLATE I}
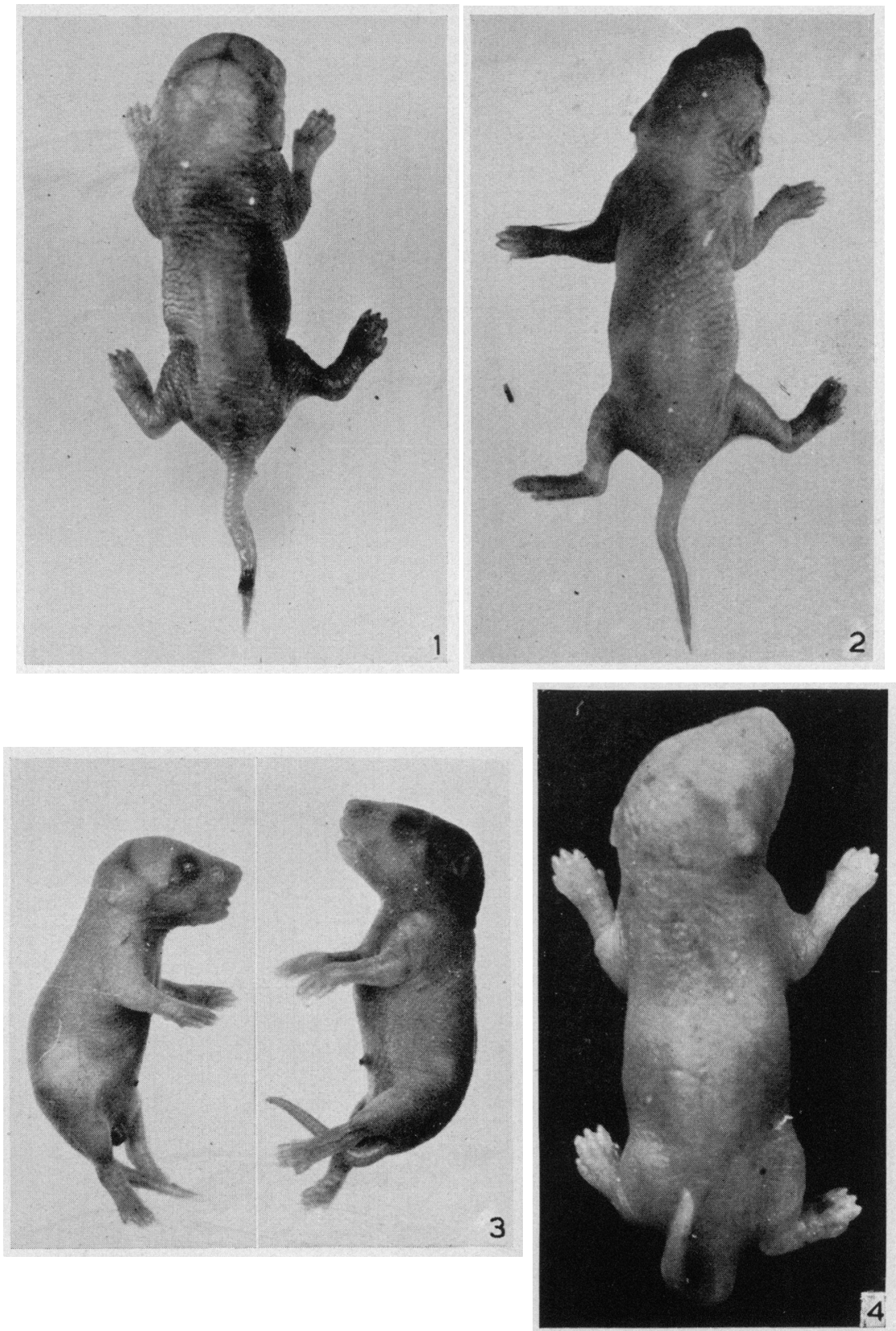

(Facing page 380) 
PLATE 2
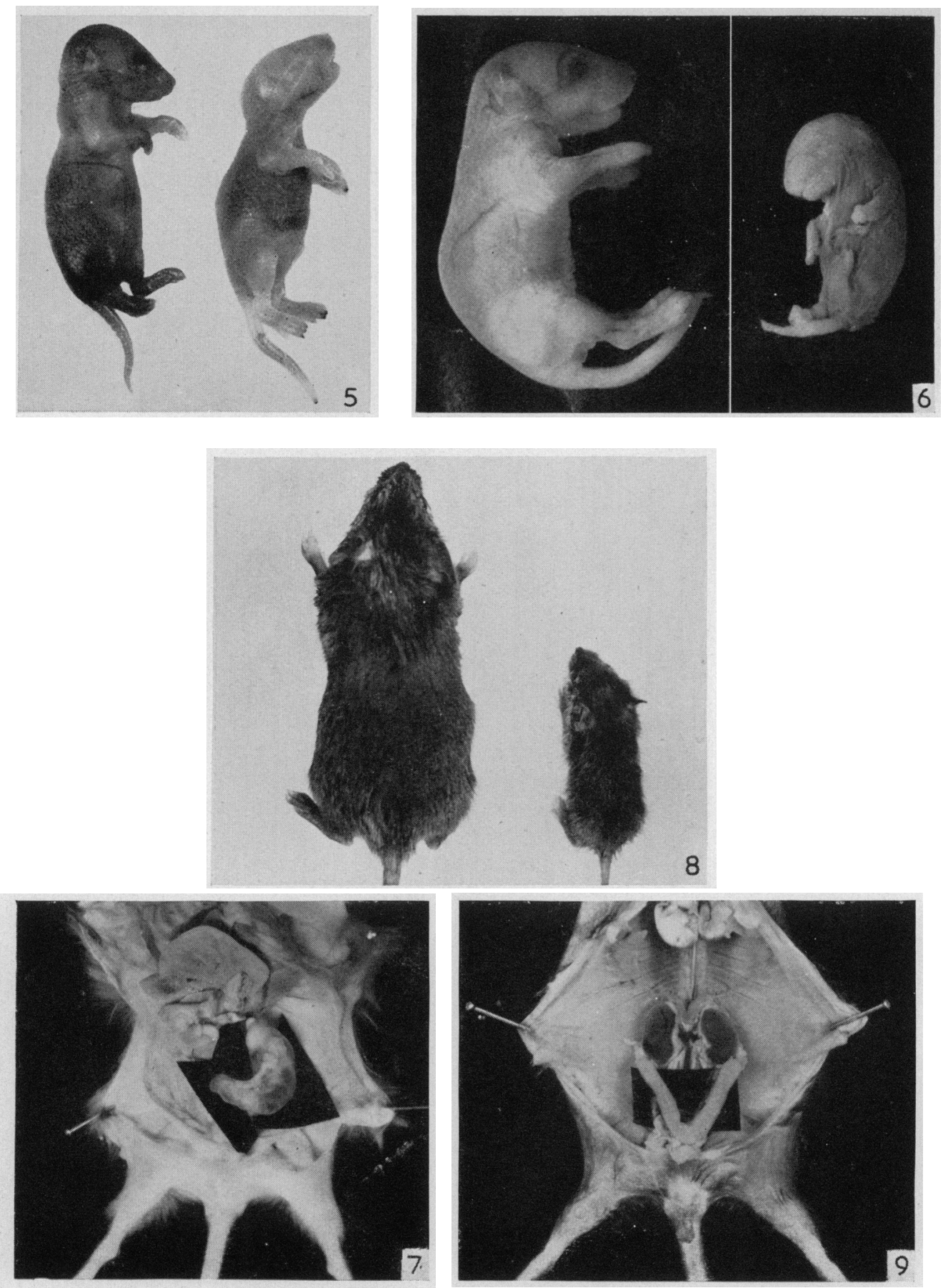

(Facing page 381) 